\title{
Resenha: Um Diálogo entre a Psicanálise e a Neurociência
}

\author{
Monah Winograd ${ }^{1}$ \\ Flávia Sollero-de-Campos \\ Pontifícia Universidade Católica do Rio de Janeiro \\ J. Landeira-Fernandez \\ Pontifícia Universidade Católica do Rio de Janeiro e Universidade Estácio de Sá
}

\section{Book Review: A Dialogue between Psychoanalysis and Neuroscience}

No último século, assistimos à invenção do computador pessoal e ao surgimento da cibernética e da inteligência artificial, fatos que mudaram radicalmente nossas vidas e costumes. Internamente ao campo das ciências do psíquico, forjamos novas metáforas e novos modelos psicológicos segundo os quais pensar é computar e processar informações.

Vimos ainda, nos anos 1970, as ciências do cérebro agruparem-se sob o título de Neurociência, defendendo a importância da arquitetura e da materialidade cerebral, não apenas como suporte do cognitivo, mas principalmente como sua determinação. A "problemática corpo/mente" recebeu roupa nova com a dicotomia hardware/software, remodelando as questões sobre a materialidade da mente e sobre os níveis de causalidade em jogo. Questões relacionadas com a estrutura/função do sistema nervoso articularam-se a outras relativas aos modos de processamento de informação (serial ou em paralelo). A metáfora do homem-máquina pareceu mais real do que nunca, pois nos vimos programados para sermos o que nos tornamos.

Durante a última década do século XX - mundialmente anunciada como "década do cérebro" - as ciências do cérebro e o cognitivismo deram as mãos, utilizando sem reservas a terminologia informacional e tratando o órgão anímico como uma super-máquina informacional. Quem não se lembra do título e do texto da série apresentada pelo Dr. Drauzio Varella no Fantástico, "Cérebro, a Super-máquina"?

Chama a atenção o fato de que, até há pouquíssimo tempo, a Psicanálise tenha se mantido alheia, sem que os motivos estejam explicitados de parte a parte. Psicanálise e Neurociência seriam epistemologicamente incompatíveis? Ou, ao contrário, pode-se positivar algum diálogo? O livro Um diálogo entre a Psicanálise e a Neurociência, do psicanalista didata da Sociedade Psicanalítica do Rio de Janeiro, Victor Manoel Andrade, publicado em 2003 pela Casa do Psicólogo, inscreve-se no centro deste debate, superando a "belle indifférence" que, para alguns, comprometia a sobrevivência da psicanálise no século XXI.

A primeira parte do livro apresenta e justifica a interface entre a psicanálise e as neurociências, trazendo à tona a problemática envolvendo o conceito freudiano de Trieb (instinto/pulsão/drive). Recontando a história da invenção da psicanálise, V. M. Andrade sublinha a neurologia em Freud e sua convicção de que fazia ciência natural. A partir daí, o autor prossegue destacando o parentesco da psicanálise com

1 Endereço: Departamento de Psicologia, Pontifícia Universidade Católica do Rio de Janeiro, Rua Marquês de São Vicente, 225 Rio de Janeiro, RJ, Brasil 22453-900. E-mail: winograd@uol.com.br a biologia e sugerindo problematicamente ser este o sentido maior do próprio termo "metapsicologia", utilizado por Freud numa carta ao seu amigo e confidente Wilhelm Fliess datada de 10.03.1898 (Freud, 1898/1986) para caracterizar a sua (de Freud) psicologia, maior do que somente uma técnica psicoterápica ou mesmo uma teoria psicológica da consciência pois traça o esquema do aparelho psíquico descrevendo sua origem, sua estrutura e seu funcionamento dos pontos de vista tópico, dinâmico e econômico. Trocando em miúdos, a metapsicologia é o núcleo da psicanálise, sua parte conceitual ou sistema teórico que sustenta todo o resto. É a inteligibilidade que ela produz ou o plano a partir do qual pensa. Uma bruxa com um caldeirão poderoso de onde borbulham idéias para entender e recortar o material da experiência.

Neste terreno, o conceito de Trieb (instinto/pulsão/drive) mostra porque é um conceito "selvagem", resistindo aos esforços de domesticação que algumas traduções propõem. $\mathrm{Na}$ verdade, Trieb é psicanalítico demais e não se deixa apreender numa só fronteira de seu campo de abrangência. Sua centralidade aponta para outra fronteira da psicanálise, desta vez, com a filosofia. Optando pela tradução do termo por "instinto", V. M. Andrade abre mão da problemática evocada pelos outros sentidos do termo alemão e pelas outras interlocuções da psicanálise.

Realizando um deslizamento dos problemas envolvendo o Trieb para a operacionalidade do conceito de "afeto", na segunda parte do livro, o autor aprofunda a noção metapsicológica de "estruturas afetivas" que se prolongam em "estruturas ideativas". A definição freudiana mais básica do afeto é ser ele, como Andrade explica, "um estágio final de um fator quantitativo, de uma energia que [Freud] chamou de quota de afeto (ou soma de excitação), isto é, o elemento metapsicológico primordial" (Andrade, 2003, p. 69). Em psicanálise, o afeto corresponde à descarga de energia no interior do corpo acompanhada de prazer ou desprazer conjugada à percepção da descarga. Inspirado pela teoria do marcador somático, elaborada pelo neurocientista português radicado nos EUA, Antonio Damásio (1993), Andrade acrescenta serem os afetos (sentimento, na linguagem de Damásio) conseqüência de dispositivos de biorregulação formados por circuitos neurais cerebrais ativados ou inibidos em função de processos bioquímicos do corpo em interação com o ambiente. Os registros mnêmicos contíguos e sucessivos das percepções das descargas formarão as idéias ou representações mais ou menos ativas e intensas.

Ao tomar o afeto como ponto de partida, todo o corpo se torna pensamento e cognição ou, nas palavras de V. M. Andrade, estamos "na presença de um psiquismo, pode-se dizer, exclusivamente corporal" (Andrade, 2003, p. 74). 
Esta remissão do psíquico ao corporal leva V. M. Andrade a concluir ser a quota de afeto o elemento não variável, comum a todos os indivíduos, adquirido filogeneticamente através de um processo de seleção natural (genótipo). Por sua vez, a representação ou a idéia associada ao afeto é o componente variável, ontogenético, específico de cada indivíduo (fenótipo) e, portanto, "depende da história das vivências afetivas experimentadas com os objetos" (Andrade, 2003, p. 83). A psicanálise freudiana mostra a sua vizinhança com a psicologia evolucionária.

A terceira parte discorre sobre alguns diálogos entre psicanálise e neurociência e destaca aspectos neurocientíficos dos fenômenos circunscritos pela psicanálise, tais como os sonhos e o inconsciente. Citando John Bowlby $(1960,1969)$ e Richard Dawkins (1976, 1995), entre outros, o autor defende a importância da consideração evolucionista dos processos biológicos nas formulações sobre as origens, as organizações e os funcionamentos da mente humana. Além do $I d$, instância psíquica espontânea por natureza e sobredeterminada filogeneticamente, também o ego traria tendências inatas, sendo a "sua linha de desenvolvimento preparada geneticamente, mesmo que não esteja pronta logo no início" (Andrade, 2003, p. 93). Para Andrade, esta observação aproxima ainda mais a psicanálise da neurobiologia, pois dá à primeira um horizonte evolucionário. Afinal, como separar um indivíduo da sua ascendência, da sua linhagem, ou em termos mais gerais, da sua espécie? Em psicanálise, a oposição entre inato e adquirido se dissolve em proveito de uma complementaridade, de modo que se torna praticamente impossível identificar um e outro separadamente. Ainda assim, Andrade sublinha a importância dos padrões pré-formados de resposta ao ambiente, o que o leva a considerar a mente como um sistema fechado cuja configuração está dada de saída, devendo ser apenas aperfeiçoada ao longo do desenvolvimento ontogenético.

Embora Andrade escreva que "a limitação da plasticidade do sistema fechado pelo design genético não a impede de ser suficientemente elástica para desenvolver o patrimônio genético através da proliferação de inumeráveis conexões sinápticas" (Andrade, 2003, p. 99), ele acredita numa anterioridade do filogenético relativamente ao ontogenético. Se rebatermos o par filogênese/ontogênese ou inato/adquirido no par natureza/cultura, veremos esta anterioridade tornar-se problemática. Como separar a natureza humana da cultura que ela produz? Como não ver a cultura sendo produzida e ao mesmo tempo produzindo a natureza humana? O que é a natureza humana, mais exatamente (por exemplo, Leach, 1985)? Como a cultura e a natureza humana produzem uma a outra? São questões que atravessam o livro de Andrade, ultrapassando seus limites.

Finalmente, a quarta parte adianta reflexões sobre a técnica. A conclusão do autor é ser "a técnica psicanalítica instrumentada pela transferência (...) a maneira mais natural de produzir efeitos neuroquímicos no organismo através apenas da relação humana" (Andrade, 2003, p. 191). De fato, sabe-se há algum tempo, graças ao desenvolvimento de sofisticadas técnicas de neuroimagem, que a psicoterapia produz transformações na atividade de áreas específicas do cérebro, alterando padrões de funcionamento também neste nível (Landeira-Fernandez \& Cruz, 1998). Mais uma vez, é preciso atentar para o risco de hierarquização entre as causas em jogo, o que levaria a um reducionismo ingênuo e infundado. É mais coerente pensar em termos de níveis explicativos do que estabelecer entre estes níveis uma relação de causa e efeito.

Embora passe ao largo da problemática epistemológica relativa a noção de ciência, central para o debate, Um diálogo entre a Psicanálise e a Neurociência revela-se um livro afirmativo no qual a potência da psicanálise se faz notar. Potência teórica porque encontramos disposição para o pensamento e produções consistentes. Potência clínica porque a eficácia da técnica psicanálitica vem sendo demonstrada empiricamente (por exemplo, Luborsky e cols., 1993). Mas, como a comprovação da eficácia não basta como prova de valor (Stengers, 1992, 1993), a neurociência vem comprovando também as explicações psicanalíticas para a memória, para o sonho, para as lacunas da consciência entre outros.

Deste modo, a psicanálise não precisa nem temer a neurociência, nem aderir irrefletidamente ao modelo que ela propõe. Ao contrário, é preciso escutá-la como quem escuta um indivíduo que traz seu discurso para dentro dos consultórios e perguntar de uma só vez sobre a sua história, sobre a imagem de pensamento que ela sugere e sobre os saberes e ações inéditos que ela permite.

\section{Referências}

Andrade, V. M. (2003) Um diálogo entre a psicanálise e a neurociência, São Paulo: Casa do Psicólogo.

Bowlby, J. (1960). Ethology and the development of object relations. The International Journal of Psycho-Analysis, 41(2), 313-317.

Bowlby, J. (1969). Attachment and loss. Londres: Horgarth Press.

Damásio, A. (1993). O erro de Descartes. Emoção, razão e cérebro humano. Lisboa: Fórum da Ciência.

Dawkins, R. (1976). The selfish gene. New York: Oxford University Press.

Dawkins, R. (1995). River out of the Éden. Londres: The Orion Pub. Group.

Freud, S. (1898/1986). Carta a Fliess de 10.03.1898. Em S. Freud (1898), A correspondência completa de Sigmund Freud para Wilhelm Fliess 1887-1904 (pp. 302-303). Rio de Janeiro: Imago.

Landeira-Fernandez, J. \& Cruz, A. P. M. (1998). Da filosofia à neurobiologia: O que o psicólogo precisa saber sobre os efeitos da psicoterapia no sistema nervoso. Cadernos de Psicologia, 4(1), 83-89.

Leach, E. (1985). Natureza/cultura. Em Enciclopédia Einaudi, 5. Lisboa: Imprensa Nacional/Casa da Moeda.

Luborsky L, Diguer L, Luborsky E, Singer B, Dichter D. \& Schmidt K. (1993). The efficacy of dynamic psychotherapies: is it true that "everyone has won and all must have prizes?' Em N. Miller, L. Luborsky, J. P. Barber \& J. P. Docherty (Orgs.), Psychodynamic treatment research: A handbook for clinical practice (pp. 497-516). New York, Basic Books.

Stengers, I. (1992). La volonté de faire science. A propos de la psychanalyse. Paris: Synthélabo.

Stengers, I. (1993). A invenção das ciências modernas. São Paulo: Editora 34.

Recebido em 10.03.2005

Aceito em 28.03.2005 